\section{Good Development}

Developmental Processes in Higher Vertebrates. By R. Bellairs. Pp. xiv + 366. (Logos: London, March 1971.) £6. IN this book the author provides a modern account of the development of amniotes, that is, of reptiles, birds and mammals or "the higher vertebrates". As far as I know no other similarly specialized treatment is available. For mammals, in particular, there are few general works, because the earlier stages of mammalian development are usually extremely hard to investigate. Most vertebrate developmental biology concerns the Amphibia which are constantly referred to, even in this book.

The first three chapters deal with general concepts; the fourth and fifth with topics special to birds; the sixth with embryonic inductions, mostly in the chick; the seventh and eighth with topics special to the early development of mammals and reptiles respectively; the final four deal with general problems, in particular the mechanisms and control of organ growth, teratology and immunology, and some of the molecular biology of development. I find this organization logical and very satisfactory from the point of view of one trying to understand developmental processes and their control rather than to assimilate experimental minutiae. As there is very little formal structure to the study of development the author is often forced to consider several conflicting explanations of the same process without being able to come to a firm conclusion, that is, she rarely finds it possible to reject an explanation on theoretical grounds. Indeed this reinforces the view that unifying principles such as Wolpert's "positional information" are vital to the development of embryology as a science.

The book contains an extremely useful, factual summary of many aspects of amniote development; it is surprisingly up to date, and it is accurate. The only failing lies in the lack of interpretation of some of the data presented, but $I$ feel that the role of the book is really to stimulate thought and experiment, rather than to supply answers. Thus it should be useful to both theorists and experimentalists and can be recommended to all biologists.

ANTHONY ROBERTSON

\section{Connecting Neurones}

Neurons and Interneuronal Connections of the Central Visual System. By E. G. Shkol'nik-Yarros. Translated from the Russian by Basil Haigh. Translation edited by Robert W. Doty. Pp. viii + 295. (Plenum: New York and London, 1971.) $\$ 22.50$.

THIS book was originally published in Russian in 1965 and has been revised and updated by the author for the English edition. Although entitled Neurons and Interneuronal Connections of the Central Visual System it is principally concerned with neurones of the visual cortical areas and, to a lesser extent, of the lateral geniculate nucleus. The neurones of these structures are described in considerable detail and several species, ranging from hedgehog to man, are examined. One is fascinated, page after page, to see the drawings of neurones which come in all shapes and sizes, from the well known pyramidal neurones to their less famous brethren, "the parasol" and "semilunar" neurones.

Although the author states somewhat towards the end of the book that "every architectonic characteristic, however trivial, corresponds to a different pattern of interneuronal connections", it is clear from the beginning that he is much impressed by cytoarchitectonic differences, and describes in some detail the different arrangement and types of cells in areas 17,18 and 19 although it is not clear whose definition of areas 18 and 19, particularly for monkey and man, is used. This limits somewhat the value of the descriptions. It seems a pity that the author should not at least refer to the studies of Lashley and Clark and of von Bonin and Bailey. These authors, to varying degrees, failed to find the cytoarchitectonic differences so confidently described by Brodman (who is mentioned). Having described the cytoarchitectonics and Golgi picture of area 17 and (the undefined) areas 18 and 19 , the author gains enough confidence to predict their connexions. For he states that "most association connections originate in areas 18 and 19, which follow from the neuronal structure of these areas... while area 17 is connected principally with subcortical structures and the periphery. This conclusion is also supported by the narrowness of layer III of area 17 in primates". Such a statement may be received with some surprise, for the fact is, of course, that area 17 has abundant association connexions in almost all species described so far.

The most interesting parts of this book are undoubtedly the sections that deal with the structure, shape, dendritic trunks and axonal branchings of the individual cells, but the rigid criteria that we now demand as proof of actual "contact" between cells are, unhappily, missing. The Golgi method, on which the description is largely based, does not and cannot, on its own, allow the identification of interneuronal contacts. The author, for example, believes that axo-axonal contacts exist in the cortex and shows a very unconvincing Golgi photomicrograph to prove his case, although axo-axonal contacts have been extremely difficult to demonstrate in the cortex by electron microscopy and must be presumed to be very rare, if indeed present at all. Many other types of contacts are described, including connexions between spines and capillaries and axonal swellings and capillaries, almost all based on light microscopy. What was reasonable evidence in Cajal's day is not sufficient evidence now.

The book abounds in speculation, frequently based on scanty anatomical evidence. All the more pity, therefore, that precious little is said of "physiological" cells among which contemporary anatomists feel much more relaxed and at home than among "anatomical" cells such as the "cup-shaped" ones. Nothing is said about "simple" and "complex" cells, for example, although in a final chapter there is much speculation on colour vision as a function of the presence and shapes of specific groups of cells in the visual pathways.

This said, however, the book is bound to have some interest to students of the cortex, if only for the descriptions of the great variety of cells that make up the cortex. In the final analysis, all these different shapes of somata must mean something, just as much as the branching patterns and course of their dendrites and axons do. The book may also help to familiarize scientists in the West with Russian literature on the subject. Much of the material referred to in the book is apparently available in Russian only and therefore presumably unknown to most workers in the West. The highly readable translation will, it is to be hoped, remedy this situation, if only slightly. S. ZEKI

\section{Hydronautics}

Hydronautics. Edited by Herman E. Sheets and Victor T. Boatwright, Jr. Pp. xvii +454. (Academic: New York and London, September 1970.) $£ 10.25$.

HYDRONAUTICS is one of those recentlycoined words which mean different things to different people. If aeronautics is the art of navigating in the air, then I would have thought that hydronautics should be the art of navigating in (and possibly on) the water: its etymology is certainly this. However, this book (to quote the preface) "treats the major scientific and engineering disciplines related to ocean technology". There are seven chapters each by a different author.

The chapter on ocean resources, by J. H. Clotworthy, is readable, well informed and includes some very sensible comments on potential exploitation. It covers the whole field from petroleum and fish to pollution (a "resource in reverse") and recreation. The only serious fault with this chapter is an almost complete lack of references, which is a pity since he so often succeeds 